WellBeing International

WBI Studies Repository

1984

\title{
Empathy, Humaneness and Animal Welfare
}

M. W. Fox

The Humane Society of the United States

Follow this and additional works at: https://www.wellbeingintlstudiesrepository.org/acwp_habr

Part of the Animal Studies Commons, Other Anthropology Commons, and the Social Psychology and Interaction Commons

\section{Recommended Citation}

Fox, M.W. (1984). Empathy, humaneness and animal welfare. In M.W. Fox \& L.D. Mickley (Eds.), Advances in animal welfare science 1984/85 (pp. 61-73). Washington, DC: The Humane Society of the United States.

This material is brought to you for free and open access by WellBeing International. It has been accepted for inclusion by an authorized administrator of the WBI Studies Repository. For more information, please contact wbisr-info@wellbeingintl.org.

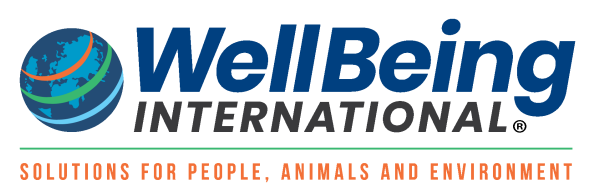




\title{
EMPATHY, HUMANENESS AND ANIMAL WELFARE
}

\author{
M. W. Fox \\ 2100 L Street, N.W. \\ Washington, D.C. 20037
}

Empathy is defined variouslyy as: the intellectual identification with or vicarious experiencing of the feelings, thoughts, or attitudes of another (Random House Dictionary); the power of projecting one's personality into and so fully understanding the object of contemplation (Oxford Dictionary); and the imaginative projection of one's own consciousness into another being (Webster's Dictionary).

Sympathy and empathy are distinctly different phenomena. Sympathy is the sharing of another's emotions, especially grief and anguish, involving pity and compassion. Empathy (from the Greek term meaning affection, and a more recent German term einfuhlung, which means "a feeling in"), entails the power of understanding and imaginatively entering into another's feelings. While the two are not mutually exclusive, empathy implies some level of objective knowledge and therefore a greater accuracy of perception and affect than are seen in sympathy, which, because it is more subjective, may be a less accurate and more intuitive way of perceiving and responding to another's emotions. In our relations with animals (as with each other), sympathetic concern may or may not be misplaced, while empathetic concern, since it includes both objective understanding (of both the animal's nature and our ethical responsibilities) and emotional involvement, is likely to be more accurate and, therefore, less often confounded by anthropomorphic projections.

Empathy is motivated by concern, the accuracy of that concern (a 
desert animal doesn't need water even if one is thirsty observing it in the Sahara) being a condition of understanding: of rational objective ("scientific") knowledge. From right understanding, right action, a compassion (and responsible stewardship) arises. The sympathetic experiences, feelings, and imaginings (of how one might feel in the other's place) that come from empathizing (i.e., the introjections of one's projections) become more accurate with experience and rational understanding. This is the key to good human relations and the humane treatment of animals.

In relation to a person's emotional rapport with an animal, is empathy possible? Sympathetic concern for animals is often judged, sometimes correctly, as being a sentimental, anthropomorphic projection. Sheer subjective sympathy toward an animal, without objective understanding of its behavior and needs, can lead to erroneous assumptions as to its well-being, and to misjudgement of others' treatment of animals as being cruel. Empathy is possible when the "feelings, thoughts, or attitudes of another" can be vicariously experienced: thus when there is objective knowledge about what an animal's overt behavior signifies, and what emotional states, intentions, and expectations such overt behavior reflects, empathy is possible. Without such objective knowledge, we have sympathy and varying degrees of anthropomorphization. Understanding and sympathy combined make empathy possible.

Empathy is a perceptual and cognitive phenomenon, not simply an anthropomorphic "humanizing" projection: it is analogous to what phenomenologist Merleau-Ponty terms lateral coexistential knowledge as distinct from objective, "vertical" (i.e., Cartesian mind over body) knowing and perceiving. Dallery (1978) illustrates this mode of perception as follows:

This is not the place to summarize Merleau-Ponty's magisterial work, The Phenomenology of Perception (1946). For our purposes, it is important to note that perception is described as the complex, always open, temporal "access" between world and perceiver. It is neither a causal process nor a process distinct from social relations, speech, or understanding (as it would be if perception were a "thought of seeing"). So in perceiving a snake, for example, I do not simply receive an impression of a sinuous form having a certain mottled pattern; I do not see a cold, indifferent fact, or have a bunch of impressions to which I might or might not endow some value depending on my feelings; I see the snake, which is to say that I see its behavior in an environment proper to it and that I "appropriate" the snake's way of being, the snake's perception of certain things around it. But I am free to regard the snake as an object and admire its beauty, or to loathe its slithering. 
There is knowledge and feeling inherent in such empathetic perception. Dallery continues:

To see the animal moving in its environment is already to "care" about the animal, since in a way I put myself in its place. I say it is foraging, or mating, or fleeing; I know what it is doing because these are analogues of my behavior...But if beasts have no interior being and are automata, as Descartes held, I cannot "think in their place." In fact, I cannot really perceive them. They become real to me only as I add to certain sensations meanings that come from my sentiment of intellect. In outline, this is the tendency of modern thought. Perception is relegated either to blind mechanisms (as in skeptical empiricism and objective psychology) or to operations of the mind (as in Cartesianism and Kantianism). For Husserl and Merleau-Ponty, this amounts to canceling out perception and losing the world (at least losing it in and by means of philosophy). Merleau-Ponty then is not speaking metaphorically when he charges both camps in the modern tradition with blindness; he does not mean blindness to things in the environment (loss of the ability to see) but blindness to the world as lived, the world as open to environments of other beasts, as providing the ground of our coexistence of being together.

This I call simply a lack of empathy, which makes us dehumanize ourselves by objectifying the world, the causes of which need careful study.

From the existential phenomenologist's perspective, the difference between detached objectivity and rational empathy can be viewed as follows. Dallery (1978) equates the former with "vertical" Cartesian, hierarchical, instrumental, perceptional knowledge and the latter with "lateral" coexistential knowledge and perception. So where does sympathy fit into this paradigm? Dallery does not answer this question. It lies, I believe, in the "lateral" or coexistential dimension as the potential bridge for rational empathy and coexistential knowledge. And it is easily inhibited by the "vertical" dimension of Cartesian thought and perception. Hence Cartesianism, while not inhibiting rational intellectual development, can impair the expression of sympathy which is a prerequisite for the development of rational empathy and moral maturity.

The Cartesian dimension is advantageous to our survival or being and the coexistential dimension vital for our becoming. In thinking and perceiving in both these objective and trans-subjective dimensions, we literally think and see both ways, a "double-vision" that reconciles the dialectical nature of reality and the duality of self and other, with the paradoxical wisdom of objective love. Then, and only then, is a mature, rationally responsible and empathetic love and 
understanding of others possible. Both meaning and fulfillment are then experienced as a kind of resonance between love and understanding: agapé and logos.

There are those who believe that since the subjective world of animals cannot be objectively weighed and measured, it does not exist. Furthermore, empathizing seems pointless since animals do not really have emotions or an inner subjective mental world, except one governed by unconscious instincts. This animal-as-machine attitude, termed Cartesianism after the philosopher Rene' Descartes who gave this attitude scientific respectability in the seventeenth century, is not the only factor that impairs our ability to empathize.

The ability to empathize may be inborn as an adaptive component of our sociobiology, and as Alice Miller (1981) has shown, lack of mature parental love and understanding can severely impair a child's empathetic development.

The experience of parents' empathetic understanding (expressed as the ability to deal supportively with the child's suffering, anxieties, and growing independence) has a significant influence upon a child's ability to love and empathize. Males, in our patriarchal society, may well show more cruelty toward animals, or justify the same, because they close off empathy more than females when faced with others' helplessness and suffering. The more intense, existential anxiety and reduced ability to empathize, plus a greater need to assume dominion over others (as power and control) in the male of our species may be rooted in the male child's greater sense of insecurity and separateness from the mother in early life. This is less intense in little girls because they have the security and connectedness of maternal gender identity. Hence women may be better able to empathize and cope with others' suffering, this sex difference being exemplified by the greater nurturing ability of females that may be more than a culturally determined sex-stereotype. The greater the sense of personal security, the less need for such distancing defense mechanisms to cope with anxiety as rationalization, denial, sublimation, objectification and reaction formation.

Those adult males who are less "feminine," empathetic and nurturing, are not necessarily less sensitive than women. Their apparent insensitivity may be attributed to an emotional closing down to varying degrees when faced with others' helplessness and suffering. This awakens their own unbearable feelings of vulnerability, fear of being hurt and of losing control or of being controlled. Fear and empathy are thus linked, when empathizing evokes the awareness and terror of one's own ultimate non-being. The fears of empathy's burdens and of losing power and control are the greatest obstacles to man's being and becoming humane. To judge such people as being deliberately cruel or 
intrinsically insensitive is surely unjust, yet this is a common reaction in the humane, animal welfare and rights movement.

Such defensive ideologies as patriarchal dominionism and Cartesianism, like machismo, are perhaps reaction formations in the service of the ego, especially of the insecure male ego, in this culture, which need to be recognized as pathologically maladaptive reaction formations.

The ability to empathize is also affected by cultural attitudes and values: emotions are put down by instrumental rationalists as being irrational and subjective. Self-serving religious and political ideologies also impair the ability to empathize, notably such ideologies as: man's God-given dominion (over women, animals and nature); of God being only transcendent and not also ominpresent, inhering in all living things. Beliefs that animals have an intrinsic right to exist, or are ensouled, or possess a spark of inherent divinity, have been dismissed as "eastern" philosophy and pagan pantheism. Yet respect and compassion toward all of God's creations is an integral part of Christianity (especially of Paulist, Gnostic and Essene doctrines).

The moral foundation of our industrial civilization's relationship with animals and nature is clearly flawed by its lack of reverence for all life. In order to further the exploitation of animals by the biomedical, farming and wildlife "resource" industries, such beliefs in man's dominion and in animals having no inherent rights, divinity or capacity to suffer emotionally, become essential defenses to rationalize away and deny empathetic feelings of compassion, guilt and responsibility.

There are a number of other reasons why empathy toward animals is impaired, leading to their being treated inhumanely or with indifference. First, we lack objective, scientific knowledge, (rather than applied production-related information) about the behavioral requirements and emotional, subjective world of animals. Farmers, animal scientists and others involved in livestock production also have little or no formal training in ethology. A stockman who knows his animals, who can "think like a pig," for example, usually does a better job than one that lacks this basic and essential knowledge.

Second, desensitization, a blunting of sensitivity, occurs naturally as a defense mechanism when one has to perform various painful procedures upon animals and must ultimately kill them or send them to slaughter. Empathy is thus withdrawn, because the burden of responsible compassion that comes with empathizing with another's suffering and helplessness awakens one's own sense of vulnerability and death awareness, which can be unbearable. Many people seem to confuse empathy with being anthropomorphic probably because they are repressing their own true feelings behind a defensive screen of intellectual rationalizations used to justify and protect vested interests in 
animal exploitation and to alleviate feelings of guilt. Closing off empathy, especially in laboratory animal research (with its scientific "objectivity") and factory farming and wildlife exploitation (with their objectification of animals as "stock," "food converters," "resources," and "trophies,") ultimately distorts perceptions and objectivity, and becomes a primary source of needless animal abuse and suffering.

Third, the empathetic burden of responsibility is lightened further by making economic and other rationalizations to justify certain procedures: i.e., that suffering is necessary, unavoidable, and justifiable if any societal benefits are accrued.

What may be termed "protective objectification" - the denial of others' subjectivity - in order to avoid closeness, responsibility, and the burdens of empathy, is another obstacle, exemplified by women being treated as "sex objects," medical patients as "cases," and animals as trophies, pets, research tools, livestock, etc. Many persons in a paradoxical and potentially stressful relationship will often mobilize the above defenses since emotional involvement can lead euphemistically to "burn-out": farmers who nurture animals that will be killed; animal shelter personnel who are concerned about animal welfare but must euthanize them; biomedical researchers and laboratory technicians who care for animals but cause them to suffer and mutilate, kill and dissect them; physicians and nurses attending the terminally ill, knowing they will soon die. While such persons must be "realists" in dealing with the paradoxes of life, the difference between a nurturing and supportive person and one who is empathetically disconnected is the difference between humaneness and indifference, between compassion and inhumanity. The difference is not between intrinsically kind and cruel persons, but between those who can bear the burden of empathy and those who fear it. The difference between a humane farm and a large "factory" farm, and regular human hospital and a hospice for the dying is surely based upon the individual's capacity to empathize and to not protectively shut out the realities of life's suffering and the finality of one's own non-being.

Protective objectification is analogous to Judaic philosopher Martin Buber's "I-It" relationship. From Buber's perspective (1970), empathy enables us to break out of the objective, detached "I-It" mind-set into the trans-subjectively objective realm of "I-Thou." The objective and subjective realms of each "It" and "Thou" are mutually inclusive: every entity is a dualistic monad. The subjective, intrinsic value or worth of one entity is part of the objective, instrumental realm of other interdependent monads (be they atoms or living beings), that are bound in relationship (which may be purely physical, ecological, social or emotional). In Buber's terms, the subjective " $I$ " of one monadic entity is the objective "It" of another. But 
when there is respect for the "I-ness" or subjective realm of another's being, and empathetic love and compassionate understanding, the objective "It" becomes another subjectively resonant, spiritual "Thou." A monadic relationship is then made, through respect and love, which is, for Man, the emotional, spiritual and ethical manifestation and experience of a unified field of being. This state of relatedness does not, I believe, as Buber suggests, exclude or transcend the "I-It" objective duality, but rather enfolds it in love, such that the objective instrumental realm is still an intrinsic part of the relationship but does not govern it.

Buber's concept of "I-Thou" embodies the spiritual and political principles of reverence for all life, humane stewardship, respect, nurturance, "reciprocal maintenance," co-evolution and agape' (as selfgiving love). Objective instrumental rationalism and love are not mutually exclusive, but rather they reconcile, at the conscious, ethical level of reality, the dialectical, paradoxical antinomies of life. The exclusion of love from objectivity brings evil and suffering into the world, which cause increasing anxiety, which in turn leads to more power and control over others or emotional withdrawal, and to more evil and suffering.

The "otherness" of an animal Buber (1970) describes eloquently when he strokes a horse at his grandparents' estate:

I must say that what I experienced in touch with the animal was the Other, the immense otherness of the Other, which, however, did not remain strange like the otherness of the ox and the ram, but rather let me draw near and touch it... and yet it let me approach, confided itself to me, placed itself elementally in the relation of Thou and Thou with me.

Buber emphasizes that an "I-Thou" rather than an "I-It" relationship is therefore possible in the absence of a reciprocal observing ego, as when one contemplates a rock, or nature, or interacts with an animal. It is possible in such moments of openness with the nonhuman world to actualize and encounter the spiritual essence of Being that inheres in all animate and inanimate forms and for Man, therefore, to discover, if not actually bestow meaning and significance, not as objective knowledge or some projected ideology of animism or panpsychism but as a panentheistic gnosis of the divinity or spiritual quality within all: an expanding state of pan-relation with the anima mundi, soul of the Earth, or God within.

Buber writes that the unity and living wholeness of a tree is manifest to those who say "Thou" and is present when they are present. It is they who grant the tree the opportunity to manifest its being, 
but most often our habitual attitudes, ways of thinking, perceiving and relating, deny us such a relationship. In Buber's words:

Spirit become word, spirit become form-whoever has been touched by the spirit and did not close himself off knows to some extent of the fundamental fact: neither germinates and grows in the human world without having been sown; both issue from encounters with the other.

That most animals are capable of experiencing and expressing affection and of enjoying life in their way, as we do in ours, and like us have interests, means that they are emotionally and cognitively, and some would say spiritually, little different from us. That we are different in terms of our power of dominion over them does not mean that we can ignore the ethical relevance of these similarities. We differ in degree and not in kind: we are not superior, but our objectifying of the world leads us to believe so as we no longer perceive the unified field of all Being.

Comparative sciences such as zoology, ethology, physiology, and psychology, reveal how sapience and sentience-intelligence and conscious sensitivity - evolve. The only differences between humans and other animals, which create no discontinuity but build upon the phylogenetic and ontogenetic sequence, are our powers of self-contemplation, creative imagination and verbal conceptualization and communication. The two axes of sapience and sentience reach their highest expression phylogenetically and ontogenetically in humans, as understanding and compassion, as the will is consciously motivated by the subjective force of love and directed by the objective power of knowledge. Knowledge applied without love is as self-serving, selflimiting and destructive as the love of narcissism's ignorance. Empathy, the synthesis of concern and sympathetic understanding of others, a quality not lacking in other animals, is the very essence of humane being.

\section{CONCLUSION: HUMANENESS AS LOVE}

Neither legislation nor moral codes can make people empathize with animals. Being humane is an attitude of heart and mind, of empathy and understanding, not simply a legal or moral injuction. At best, laws and codes guide and constrain human actions, but they do not inspire the ability to "love thy neighbor (and fellow creatures) as thyself." The one strong point of animal rights philosophy is that it draws our attention to the animals' own wants, intrinsic worth and interests. This implies that we and they have something in common: a will, a life of one's own, perhaps a soul. This is speaking closer to the 
heart. Recognition of these qualities in other beings awakens the heart of humility and compassion, fundamental tenets of all religious teachings. Being humane thus entails the spiritual recognition and affirmation, through empathy, humility, and compassion, of the divinity and sanctity of Self within all beings, within one's own self as well as within others.

The Buddha proclaimed: "One thing only do I teach: suffering and cease of suffering. Kindness to all living creatures is the true religion."

Likewise Pantanjali (circa 300 B.C.) gave the first step in yogic (religious) discipline as "the avoidance of injury to all living creatures," because all creatures were regarded as being part of God's creation and therefore sacred and ensouled with a spark of the Divine.

Humaneness is an expression of mature love that resacralizes nature, and all living things, not animistically but panentheistically in accord with the Christian (Paulist, Gnostic and Essene) doctrines of a divine omnipresent (as well as transcendent) Creator within all of creation, which is the basis of Schweitzer's theosophy of reverence for all life.

Empathy is the bridge for unconditional love, a love synonymous with experiencing the world without the domination of personal interests and preconceptions. Such a mature love is therefore revelationary, since it is the perception of the miraculous, of the numinously radiant divinity in all. This is the subjective recognition of Self in other, and thus of self-realization.

Through empathy, mature love is possible: such love is nondialectical in its arbitrary, unconditional non-duality of the observer (the lover) and the object of one's contemplation (as I-Thou). And love is paradoxical, for instead of losing one's sense of individuality, the sense and meaning of self is enhanced. Love transcends the paradoxical dualities of the subject-object manifolds of our every day enculturated reality, consciousness, and unconscious ego defenses. Love is revolutionary, because through the bridge of empathy, understanding as coexistential knowledge, is possible. This is the beginning of selfrealization; of personal and interpersonal development and human evolution.

Gilligan (1983) links empathy with moral maturity. When both intellect and empathy are integrated in our thinking, "it joins the heart and the eye in an ethic that ties the activity of thought to the activity of care." Without such an integration, purely intellectual, rational thinking is objectifying and potentially alienating, since it limits empathetic understanding. A purely sympathetic response is a subjective projection and potentially inappropriate, and no less damaging, than a purely objective response. Informed sympathy is empathy, expressed 
as compassionate understanding. Rational empathy is the only basis for ethically responsible behavior.

Insofar as the humane movement is concerned, and humane education in particular, to evoke sympathy for mistreated animals (for fund-raising purposes or to stimulate students' and supporters' moral indignation) is unethical if it is based only upon the sentiment of abolishing all suffering and not also upon respect for animals' intrinsic worth and recognition of the importance of humane ethics and reverence for all life to our moral development and social change.

We live in two worlds: the objective and the subjective. When we make the two worlds one, and put the inside on the outside, as Jesus once said, we will discover the Kingdom of Heaven, or in modern parlance, reality as a unified field of being. As animals, we live in our subjectivity, and as rational beings we stand apart from the world in our intellectually rational objectivity. In the one is kinship; in the other, power: but together we have the possibility of mature, responsible relationship and planetary stewardship. Apart, we have delusion, oppression, and destruction, creating the imbalances that we perceive as evil, and experience as suffering. By introducing empathy and using power and control over life in order to avoid the feelings of vulnerability and helplessness in the face of life's burdens of suffering and death, we cause even more suffering. The barrier between these two worlds, which Buber termed "I-It" and "I-Thou", is not our objectivity, or our subjectivity. Both are essential attributes of our being and becoming. But they must become integrated with the unified field of our own being that embraces animals and nature, for we are both. To perceive and think otherwise is to remain unintegrated, which is the ultimate barrier to our self-realization and moral maturity. We, animals and Nature are one. In order to change the world, we must first become as one with the world (in peace and harmony). And since peace comes from within, we must first see to ourselves before we can change the world. Then the way of empathy is clear.

\section{POSTSCRIPT}

\section{Why Do Animal Shelters Kill So Many Pets?}

Psychiatrist M. Scott Peck in A Road Less Travelled draws a very pertinent, which some would see as impertinent, correlation between the love people have for their pets and the high rate of divorce among G.I.'s who lost affection for their Viet Nam and Korean wives as they began to learn English, and assert their no longer dependent and subordinate individuality. Puppies and kittens likewise lose their appeal to many as they mature, assert their independence and individ- 
uality. And so like G.I. brides, they are abandoned because, beneath the complaints that they are disobedient, too much trouble, or have annoying habits and behavioral problems, they are no longer loved.

The mass destruction of some 13 million unwanted, abandoned, and neglected cats and dogs each year in the U.S. must assuredly reflect the limitations of an immature, narcissistic love relationship, an aspect of the human-companion animal bond which has been grossly neglected by researchers and is not simply a consequence of "unthinking and uneducated" owners. Peck defines mature love as "the will to extend one's self for the purpose of nurturing one's own and another's spiritual growth." In our relationships with captive and domesticated animals, this is surely the essence of humane husbandry. It is the absence of empathy, compassion and understanding, which undergirds all inhumane and unethical relations between people and between us and the animals, as they continue to be exploited for selfish, emotional, financial, and other reasons.

Farmers and biomedical researchers can put their empathy, compassion, and understanding of animals on one side for reasons of profit and instrumental utility, arguing that the extreme privations of factory farming and mental and physical suffering of laboratory cats, dogs, primates, and other animals, is for the "benefit of society." A society that can find anything of greater value than empathy, compassion, and wisdom is perhaps suffering from the pathology of materialism and objectivity. The divorced G.I.'s bride was simply the material of his narcissistic yearnings; a sexual object. Likewise cats and dogs can be status or play objects, or things to fondle or control; and farm animals simply biological machines in the computerized technology of agribusiness; and laboratory animals mere components of experimental design and ultimate execution.

Fortunately not all husbands (G.I.'s) and husbanders (pet owners, farmers, and biomedical researchers) relate to other living beings in this way. But unfortunately, we must surmise that they are a minority, for to date they have been relatively silent on matters concerning human and animal rights. Or are they the silent majority? It is surely time to break the silence, after reflecting upon the monetary value of animals, for as Jesus said: "Do not two sparrows sell for a coin of small value? Yet not one of them will fall to the ground without your Father's knowledge; not one of them goes forgotten before God." (Matthew 10:29; Luke 12:6).

It is too simplistic to say that people love their pets because pets are "nonthreatening others." Perhaps by understanding why so many people find it easy to love animals, we may discover ways to help people love each other, and not be afraid to love, and those who hate, fear, 
or are indifferent toward animals, love them also, as significant, rather than as nonthreatening, others.

If love is the union of souls, then the bridge is empathy when such non-sentimental love is based upon compassion, respect, and understanding. Such love entails an openness of feeling, a degree of vulnerability, intolerable in the presence of any human or animal that is perceived, correctly or incorrectly, as being threatening. Fear inhibits the ability to give and receive love. Likewise, others' expectations that we feel we must live up to, set up defenses and roles. But with animals (and little children) when we have no fear toward them, and they have no demanding expectations of us, then we are free to love them.

Mature love is also impaired when the object of one's perception and even claimed affection, is exploited to one's own selfish advantage. Such exploitation, be it of a spouse or an animal companion (as a "pet," or for its pelt, meat, or physiological responses to test drugs), objectifies the potential "Thou" of the others' being into an "it" (a sex object, a child-substitute, a financial or intellectual gain, etc.). These objectifying transformations may seem necessary for our well-being, and to a degree they are. But when we transgress ethical boundaries in relating to others exploitatively rather than with empathetic understanding and respect, we limit our own potential fulfillment from such a relationship. This fulfillment is to become human, or even, as Plato and Aristotle envisioned, to "become like divinity as much as that is within our power." 


\section{REFERENCES}

Buber, M. 1970. I and Thou, Walter Kaufman transl. New York:Scribners.

Dallery, C. 1978. In:Fox, M.W. and Morris, R.K. eds. On the fifth day: Animal rights and human ethics. Washington, D.C.:Acropolis Press. pp. 70-92.

Gilligan, C. 1983. In a different voice. Boston: Harvard University Press. Miller, A. 1981. Prisoners of childhood. New York:Basic Books. 